\title{
Genetic parameters, path analysis and indirect selection of agronomic traits of cassava germplasm
}

\author{
RAFAEL P. DINIZ ${ }^{1,2}$ and EDER J. DE OLIVEIRA ${ }^{2}$ \\ ${ }^{1}$ Centro de Ciências Agrárias, Ambientais e Biológicas, Universidade Federal do Recôncavo da Bahia, \\ Rua Rui Barbosa, 710, 44380-000 Cruz das Almas, BA, Brazil \\ ${ }^{2}$ Embrapa Mandioca e Fruticultura, Rua da Embrapa, Caixa Postal 007, \\ 44380-000 Cruz das Almas, BA, Brazil
}

Manuscript received on April 25, 2018; accepted for publication on November 5, 2018

\begin{abstract}
How to cite: DINIZ RP AND OLIVEIRA EJ. 2019. Genetic parameters, path analysis and indirect selection of agronomic traits of cassava germplasm. An Acad Bras Cienc 91: e20180387. DOI 10.1590/10.1590/0001-3765201920180387.
\end{abstract}

\begin{abstract}
This study aimed to estimate genetic parameters and correlations between morphological, agronomic and root quality traits of cassava plants, as well as to study cause and effect relationships through path analysis. A total of 814 genotypes were evaluated from 2011 to 2015. The joint analysis of the data was performed by the mixed models approach. The predicted genetic values of the genotypes were used to estimate the genetic correlations among as well the path analysis. The estimates of heritability of the genotype means ranged from 0.31 (commercial fresh root yield - CRY) to 0.62 (plant height - PLH). The highest genetic correlation coefficient estimates were observed for starch yield (STY) $\times$ total fresh root yield (FRY) (0.97). The results of the path analysis showed that FRY had the highest direct effect on STY, but the indirect selection based on FRY was not efficient to improve the gain of STY.
\end{abstract}

Key words: Manihot esculenta Crantz, heritability, correlation, correlated response.

\section{INTRODUCTION}

The selection of superior cassava clones (Manihot esculenta Crantz) is generally carried out based on phenotypic (Ceballos et al. 2013) or genotypic estimates of certain traits (Oliveira et al. 2014). These authors mention that heritability of some agronomic traits of cassava have low magnitude, which can directly influence the gain obtained from selection. In contrast, there are increasing demands to phenotype large numbers of genotypes in germplasm banks and breeding programs with high speed and accuracy but low cost. Therefore, alternative methods such as indirect selection can improve genetic gains, since existence of tightly correlated traits allows eliminating the trait with difficult measurement, thus allowing evaluation of a larger number of genotypes in each stage of selection. For this purpose, knowledge of the level of association between traits is essential to prioritize the selection process.

Correspondence to: Eder Jorge de Oliveira

E-mail: eder.oliveira@embrapa.br

ORCid: https://orcid.org/0000-0001-8992-7459 
The traits related to cassava root quality, such as contents of amylose, cyanogenic compounds, carotenoids, dry matter and starch, have low genetic correlations (Esuma et al. 2016, Oliveira et al. 2014). Therefore, indirect selection may not be a suitable strategy in breeding programs. In contrast, when analyzing morphological and productivity traits, the estimates of genetic correlations are of medium to high magnitude (Gomes et al. 2007, Lenis et al. 2006, Mulualem and Ayenew 2012, Ojulong et al. 2010), which makes it possible to obtain good genetic progress using indirect selection. Nevertheless, studies to identify correlations of morphological, production and root quality traits are still incipient for cassava, so additional research into the use of these traits for indirect selection in breeding programs is necessary.

Although correlation coefficients have good applicability in breeding programs, the estimates of these parameters on their own do not shed light on the cause and effect relationships, as well as the relative importance of direct and indirect effects among the traits (Cruz et al. 2012). In contrast, correlation coefficients can be partitioned via path analysis, which provides detailed knowledge of influences of traits in a previously established diagram. By path analysis, it is possible to estimate the existence of correlation and the cause and effect relationship between secondary traits of a main variable. These estimates help breeders to make decisions about what strategies to follow during selection cycles to maximize genetic gains from indirect selection. Path analysis has been used in studies with cassava to exploit the relationship between traits in the selection of superior clones (Gomes et al. 2007, Mulualem and Ayenew 2012).

According to Gomes et al. (2007), indirect selection for the development of high-yield cassava clones should take into account plants with higher number of roots and greater shoot weight. In addition, Mulualem and Ayenew (2012) evaluated 35 cassava accessions collected in different regions of Ethiopia and concluded that plant height, shoot diameter and root diameter can be used to select accessions with higher fresh root weight. Regardless the trait, the efficiency of indirect selection has been demonstrated when the estimate of the heritability of the main variable has low magnitude in relation to the secondary traits, with high values of the correlation between the two traits (Falconer and Mackay 1996). Another fact that justifies the use of indirect selection is the high cost and time-consuming work to measure the main trait directly.

Specifically, starch yield is a trait in cassava breeding that is hard to measure, although it is the main desired attribute of cassava varieties used for industrial purposes because the farmer's payment is based on starch content in the roots. Starch yield is indirectly determined by the root dry matter content and fresh root yield. The heritability estimate of starch yield has low magnitude in breeding experiments of new sexually generated clones (single row plots). Oliveira et al. (2014) reported starch yield has correlations of 0.36 and 0.46 with the dry matter and amylose content. However, these two traits are also slow and difficult to measure, so they are not recommended for indirect selection. Information on associations of starch yield with other traits is scarce, so it is not possible to infer whether indirect selection would be a feasible alternative to adopt in cassava breeding programs. The objectives of this work were to estimate genetic parameters and correlations between morphological, agronomic and root quality traits, to better understand the cause and effect through path analysis, in order to elucidate the relationship between starch yield and other important traits in cassava using historic data from different genotypes.

\section{MATERIALS AND METHODS}

\section{GENOTYPES AND EXPERIMENTAL AREA}

Cassava accessions (landraces and improved varieties) from the Cassava Germplasm Bank of the Embrapa Mandioca e Fruticultura were evaluated as part of the cassava breeding program. The experiments were set 
up in two locations in Bahia state (Brazil), Cruz das Almas, and Laje, located at 13॰10'56" S and 39 25'30" W, respectively, both with altitude of $190 \mathrm{~m}$. The climate according to the classification of Köppen is tropical, hot and humid (Aw to Am). The combination of site and season was called environment to undertake the statistical analysis.

\section{EXPERIMENTAL DESIGN AND EXPERIMENTS}

A total of 814 cassava accessions were evaluated in 21 experiments conducted from 2011 to 2015 . The experiments were carried out in a completely randomized block design for two environments in 2011 and one environment in 2015, while for the other 18 environments, the genotypes were evaluated in an augmented block design, using local and improved varieties as checks for all 18 environments. Some of the 814 accessions were not evaluated in all environments.

Each experiment was established by plating $20 \mathrm{~cm}$ cuttings, which were distributed in a row with about $10 \mathrm{~cm}$ depth. The plots were constituted of 16 plants spaced $0.80 \mathrm{~m}$ apart and $0.90 \mathrm{~m}$ between rows. Crop management as well as additional water supply via sprinkler irrigation was performed when necessary.

\section{MEASURED TRAITS}

The traits evaluated were: plant vigor (VIG) - measured in the fourth month after planting, using a scale from 1 to 4, in which 1 designates plants with poor development and low vigor, with the canopy $20 \mathrm{~cm}$ diameter; 2 designates plants with intermediate vigor and development, with the canopy having $22 \mathrm{~cm}$ to $30 \mathrm{~cm}$ diameter; 3 designates plants with high vigor and good development, with having $32 \mathrm{~cm}$ to $40 \mathrm{~cm}$ diameter; and 4 designates plants with excellent vigor and development, with canopy having diameter from $42 \mathrm{~cm}$ to $60 \mathrm{~cm}$.

The harvest was carried out 12 months after planting and the following traits were measured: plant height (PLH - in meters); commercial fresh root yield (CRY - in $\mathrm{t} \mathrm{ha}^{-1}$ ); total fresh root yield (FRY - in $\mathrm{t} \mathrm{ha}^{-1}$ ); above-ground yield ( $\mathrm{AGY}-$ in $\mathrm{t} \mathrm{ha}^{-1}$ ); dry matter content in the roots (DMC - in \%), measured using the specific gravimetric method (Kawano et al. 1987); starch yield (STY - in t ha ${ }^{-1}$ ), estimated by the multiplication of FRY and STY (DMC - 4.65); leaf retention (LFR), evaluated using a scale where 1 designates plants with leaf retention less than $10 \%$ of the plant height with leaves; 2 denotes plants with leaf retention from $11 \%$ to $25 \%$ of the plant height with leaves; 3 is assigned to plants with leaf retention about $26 \%$ to $50 \%$ of the plant height with leaves; 4 pertains to plants with leaf retention about $51 \%$ to $75 \%$ of the plant height with leaves; and 5 denotes leaf retention superior to $75 \%$ of the plant height with leaves. For all the traits but PLH, all the plants in the plot were measured. Plant height was measured in five plants per plot.

\section{DATA ANALYSIS}

The joint analysis of the data for the 21 environments was performed using the linear mixed model for incomplete block design in several locations: $\mathrm{y}=X r+Z g+W b+T i+\mathrm{e}$, in which $y$ is the data vector; $r$ is the vector of fixed effects of replication in all environments added to the overall average; $g$ is the vector of random genetic effects; $b$ is the vector of random effects of blocks; $i$ is the vector of random genotypes by environments' interaction; $e$ is the vector of random errors; and $X, Z, W$ and $T$ are incidence matrices that associate the the effects of $r, g, b$ and $i$, respectively, to the data vector $y$. Since the combined analysis 
was performed considering experiments with different designs, two fixed effects related to the designs were created and adjusted according to Resende (2016) to increase the accuracy of the prediction of genetic values. The effect of replication was replaced by the effect of the design, so that according to Resende (2016) the effect of the block was adjusted within each design used.

Estimates of the coefficients of the individual broad-sense heritability of the block and the heritability of the mean genotype values, the selective accuracy and the overall phenotypic mean were obtained as described in Oliveira et al. (2014). From the predicted genetic values of the genotypes, estimates of genetic correlations among the traits were obtained using the "corrgram" package of the R v.3.3.1 program (R Development Core Team 2016).

For the path analysis, the matrices of genetic correlations involving all traits were tested for multicollinearity using the condition number test (NC), proposed by Montgomery et al. (2012), which consists of the ratio between the largest and the smallest eigenvalue of the correlation matrix. The multicollinearity (9.7) was considered weak. Path analysis was performed considering starch yield as the basic variable (main dependent), and the other seven traits were considered as independent or explanatory variables, using the GENES software (Cruz 2013). The relation between the correlated response and the gain from direct selection was also estimated through the equation proposed by Falconer and Mackay (1996): $[R C]_{(\mathrm{Y}(\mathrm{X}))} /(G S)_{\mathrm{Y}}$, where $[R C]_{(\mathrm{Y}(\mathrm{X}))}$ is the correlated response of the total fresh root yield $(\mathrm{X})$ on the starch

yield ( $\mathrm{Y})$, which can be expressed by $\left(\mathrm{i}_{\mathrm{X}} \times \mathrm{h}_{\mathrm{X}}^{2} \times \mathrm{r}\left(\mathrm{P}_{x y}\right)\right) ;(G S)_{\mathrm{Y}}$ is the gain of the direct selection for starch yield $(Y)$, as expressed by $\left(i_{y} \times h_{y}^{2}\right) ; i_{x}$ and $i_{y}$ are the values of the selection intensity for total fresh root yield and starch yield, respectively; $\mathrm{h}_{\mathrm{x}}^{2}$ and $\mathrm{h}_{\mathrm{y}}^{2}$ are the estimates of heritability for total fresh root yield and starch yield; and $\mathrm{r}\left(\mathrm{P}_{x y}\right)$ is the genetic correlation between these two traits.

\section{RESULTS AND DISCUSSION}

\section{GENETIC PARAMETERS OF CASSAVA GERMPLASM}

The selective accuracy values ( $\widehat{\mathrm{r}}_{\mathrm{gg}}$ ) ranged from 0.55 to 0.65 for CRY, FRY, AGY and STY (Table I), which are considered to be in the moderate accuracy range, whereas for VIG, LFR, PLH and DMC the values were higher than 0.70, and were considered of high accuracy according to Resende and Duarte (2007). High values of selective accuracy for dry matter content (0.90) and starch yield (0.92) were also reported by Oliveira et al. (2014) in evaluating 471 cassava accessions. The smaller selective accuracy observed in the present work may be due to the greater magnitude of the prediction error variance as well as the magnitude of the genetic variance, both used to estimate the selective accuracy of the random effects of accessions (Resende and Duarte 2007). Moreover, we evaluated almost twice as many accessions in a larger number of environments, so these results were consistent with what was expected for traits that can be influenced by several genes and the environment.

The coefficients of the individual broad-sense heritability $\left(\mathrm{h}_{\mathrm{i}}^{2}\right)$ were low for all the traits, ranging between 0.11 and 0.24 (Table I). The high error variance might have influenced the low values of $h_{i}^{2}$ since this component presented high magnitude when compared to the genotypic variance. The high estimate of the error variance might have been due to the augmented block design used in most environments to evaluate the genotypes, associated with the fact that some genotypes were evaluated in only one environment. In 
TABLE I

Genetic and phenotypic parameters estimated for plant vigor (VIG), leaf retention (LFR), commercial fresh root yield

(CRY), total fresh root yield (FRY), above-ground yield (AGY), plant height (PLH), dry matter content (DMC) and starch yield (STY) of 814 cassava accessions.

\begin{tabular}{ccccccccc}
\hline Parameters $^{\#}$ & VIG & LFR & CRY & FRY & AGY & PLH & DMC & STY \\
\hline$\sigma_{\mathrm{g}}^{2}$ & 0.10 & 0.32 & 229.14 & 333.87 & 237.24 & 0.04 & 33.24 & 32.98 \\
$\sigma_{\mathrm{b}}^{2}$ & 0.06 & 0.23 & 731.40 & 600.32 & 712.97 & 0.03 & 52.24 & 59.70 \\
$\sigma_{\mathrm{i}}^{2}$ & 0.09 & 0.24 & 609.81 & 678.90 & 601.57 & 0.04 & 27.87 & 59.09 \\
$\sigma_{\mathrm{e}}^{2}$ & 0.38 & 0.49 & 496.32 & 567.52 & 532.51 & 0.06 & 32.83 & 53.76 \\
$\mathrm{~h}_{\mathrm{i}}^{2}$ & $0.16 \pm 0.02$ & $0.25 \pm 0.03$ & $0.11 \pm 0.01$ & $0.15 \pm 0.01$ & $0.11 \pm 0.01$ & $0.24 \pm 0.01$ & $0.23 \pm 0.01$ & $0.16 \pm 0.01$ \\
$\mathrm{~h}_{\mathrm{m}}^{\mathrm{i}}$ & 0.54 & 0.50 & 0.31 & 0.42 & 0.33 & 0.62 & 0.50 & 0.43 \\
$\widehat{\mathrm{r}}_{\mathrm{gg}}$ & 0.73 & 0.71 & 0.56 & 0.65 & 0.57 & 0.79 & 0.71 & 0.66 \\
$\hat{\mathrm{X}}$ & 2.25 & 1.80 & 16.01 & 20.52 & 23.63 & 2.00 & 35.67 & 6.47 \\
\hline
\end{tabular}

\# $\sigma_{\mathrm{g}}^{2}$ : genotypic variance; $\sigma_{\mathrm{b}}^{2}$ : environmental variance between blocks; $\sigma_{\mathrm{i}}^{2}$ : variance of genotype x environment interaction; $\sigma_{\mathrm{e}}^{2}$ : error variance; $\mathrm{h}_{\mathrm{i}}^{2}$ : individual broad-sense heritability; $\mathrm{h}_{\mathrm{m}}^{\mathrm{i}}$ : heritability of the genotype means; $\widehat{\mathrm{r}}_{\mathrm{gg}}$ : selective accuracy; $\mathrm{X}$ : overall mean.

contrast, low magnitude of $h_{i}^{2}$ is common for quantitative traits, and as a rule leads to moderate or high magnitudes of heritability of the genotype means $\left(\mathrm{h}_{\mathrm{m}}^{2}\right)$.

The increases in the estimates of $\mathrm{h}_{\mathrm{m}}^{2}$ when compared to those for $\mathrm{h}_{\mathrm{i}}^{2}$ were of the order of 0.38 for VIG, 0.25 (LFR), 0.20 (CRY), 0.27 (FRY), 0.22 (AGY), 0.38 (PLH), 0.27 (DMC) and 0.27 for STY (Table I). Therefore, the estimates of $\mathrm{h}_{\mathrm{m}}^{2}$ were of median magnitude for most of the traits, ranging from 0.31 to 0.62 (Table I). For VIG and PLH, the estimates of 0.54 and 0.62 (Table I) imply less complexity, so the selection of the phenotypic values can lead to moderate gains in the different breeding phases. Vigor is an important trait to consider in the selection cycle because it is associated with the rapid development of plants and consequent coverage of the area, which reduces the incidence of light on the ground as well as the emergence and weeds. Thus, a selection of plants with greater vigor may favor cassava crop development. For PLH and VIG, selection based on the phenotype may be favorable to obtain improved populations with higher plant height. Cassava plant height is associated with the plant's ability to generate propagation material for new plantings. Therefore, disregarding plant architecture, greater plant height can be a success factor for new cassava cultivars.

The magnitude of 0.50 for LFR (Table I) allows inferring that $50 \%$ of the observed phenotypic variation between the accessions can be inherited by the offspring. Similar results were reported by Lenis et al. (2006), who obtained a value of 0.55 for the coefficient of heritability in a preliminary evaluation of 110 cassava clones under normal water supply and under water stress. According to these authors, LFR has a direct relation with both dry matter content in the roots and fresh root yield. It is also important for the development of cultivars that are fit for animal diets, where a large amount of biomass is needed.

Among the traits associated with the above-ground part of the plant, AGY presented the lowest estimate of $\mathrm{h}_{\mathrm{m}}^{2}(0.33)$ (Table I). The means that most of the variation observed among accessions was probably due to environmental effects, so the selection gain may be small. For cassava accessions, there is great genetic 
variability for several traits, among them characteristics important for the development and establishment of the crop, such as vigor, architecture and height. On the other hand, interference from neighboring plants may be a factor directly associated with the low consistency of performance of the genotypes in the evaluated environments, increasing the error variance and reducing the heritability values. Moreover, plants with rapid development and branching typically have a larger canopy diameter, increasing competition for solar radiation with nearby plants. In this sense, Tokatlidis (2017) emphasized that performance depends not only on the growth of the plant itself in the environment, considering competition for resources, but also on the competitive influence of neighboring plants. For cassava, few studies have evaluated the effects of neighboring plot competition on the performance of genotypes. However, knowledge of the effects of neighboring plot competition is essential for adequate agronomic experimentation methods and data analysis. The inclusion of this information as covariate in the model to predict the genetic values of genotypes should improve selection accuracy.

The estimate of $\mathrm{h}_{\mathrm{m}}^{2}$ for CRY was 0.31 , while for FRY it was 0.42 (Table I). Commercial cassava roots must meet the standards demanded by the consumer market, such as shape, diameter and length. However, there is no criterion defined in the literature for this purpose. At harvest time, roots used to quantify CRY were visually separated by experienced workers based on a pattern established previously by the grower. Accordingly, since in visual selection errors are likely to occur, the estimates of error variance increased, while the magnitude of the estimates of $\mathrm{h}_{\mathrm{m}}^{2}$ for CRY decreased. On the other hand, taking into consideration FRY, all roots in the plot were quantified and weighed, with no selection, which may have resulted in a higher estimate of $\mathrm{h}_{\mathrm{m}}^{2}$ for FRY. The estimate of $\mathrm{h}_{\mathrm{m}}^{2}$ for FRY can be considered moderate, which is expected for quantitative traits. However, gains with selection can be obtained by the selection of accessions.

\section{GENETIC CORRELATION COEFFICIENTS}

The estimates of the genetic correlations between the agronomic traits had variable magnitudes, although they all were positive and different from zero, except for the estimate between VIG and DMC, which can assume a value of zero, being considered null (Figure 1). FRY and STY showed a positive and strong linear association (0.97), which is consistent with the fact that on average, $25 \%$ of the weight of the fresh cassava root is starch (Nuwamanya et al. 2009).

The association between VIG and other traits, with the exception of DMC, were all positive with magnitudes ranging from 0.18 to 0.35 (Figure 1). Regarding the eight traits, plant vigor was the only one measured in the first stages of development of the plants (around three to four months after planting). The other traits were evaluated only at harvest time. Therefore, significant associations between plant vigor and other traits are of interest, because this allows the use of indirect selection, in turn allowing early disregard of genotypes, saving financial and human resources for the next stages of evaluation. However, VIG was not a good predictor of the performance of the plants because of the low genetic correlation coefficients with the main agronomic traits such as FRY and STY.

Leaf retention had a positive and non-zero linear association with all traits, with magnitudes varying from $0.15(\mathrm{LFR} \times \mathrm{DMC})$ to $0.39(\mathrm{LFR} \times \mathrm{AGY})($ Figure 1$)$. LFR is a physiological advantage by which fresh root yield increases with good management of water supply, so it was taken into account for the selection of cassava clones in preliminary yield trails (Lenis et al. 2006). These authors reported estimates of genetic correlation coefficients between leaf retention and plant height, fresh root yield, above-ground yield and dry matter content of $0.12,0.43,0.48$ and 0.45 , respectively, higher than those found by us, except for LFR 


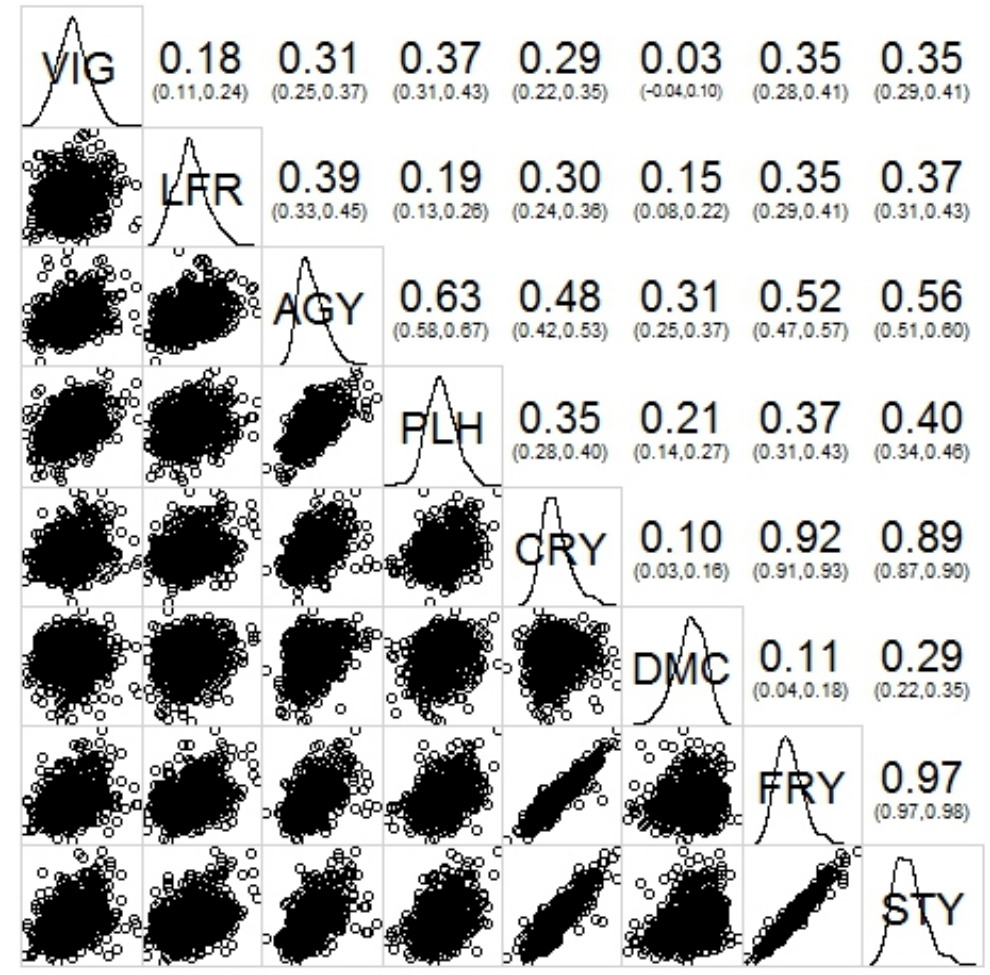

Figure 1 - Pairwise genotypic correlation coefficients between eight agronomic traits evaluated in cassava genotypes. VIG: plant vigor; LFR: leaf retention; AGY: above-ground yield; PLH: plant height; CRY: commercial fresh root yield; DMC: dry matter content; FRY: total fresh root yield; STY: starch yield.

and PLH. These differences can be attributed to the greater accuracy reported by Lenis et al. (2006), who evaluated only superior clones in trials with more replicates. In the present study, about $99 \%$ of the genotypes evaluated were germplasm accessions and the remaining $1 \%$ were improved varieties.

\section{PATH ANALYSIS}

Path analysis was undertaken based on the genetic correlation matrix of the agronomic and productive traits of cassava germplasm. The results showed that a large portion of the variation in STY is explained by the effect of the measured traits (Table II). An important step in path analysis is the composition of the causal diagram so that the relationship between traits can explain the expression of the basic variable. The seven traits were responsible for more than $97 \%$ of the variation of STY and the residual variance was low, allowing inferences about the composition of the causal diagram. In contrast, Mulualem and Ayenew (2012) reported high estimates of residual variables, considering FRY as a basic variable, and suggested using other traits to compose a diagram in future works.

The magnitudes of the direct effects of VIG, LFR, AGY, PLH and CRY on STY were lower than the estimates of their respective genetic correlation coefficients (Table II), indicating a possibility that other traits influence both the magnitude and direction of these correlations. According to Cruz et al. (2012), the correlation can be the result of an indirect contribution of one or more traits. The path analysis showed that 
TABLE II

Estimates of the direct (D) and indirect (I) effects of the independent variables on starch yield (STY) through path analysis based on genetic correlations from the evaluation of 814 cassava genotypes.

\begin{tabular}{ccccccccc}
\hline Effect & Trait & VIG & LFR & AGY & PLH & CRY & DMC & FRY \\
\hline D & STY & 0.0141 & 0.0105 & -0.0070 & 0.0073 & -0.0364 & 0.1835 & 0.9783 \\
I & VIG & - & 0.0025 & 0.0043 & 0.0052 & 0.0040 & 0.0004 & 0.0048 \\
I & LFR & 0.0018 & - & 0.0041 & 0.0020 & -0.0032 & 0.0016 & 0.0036 \\
I & AGY & -0.0022 & -0.0027 & - & -0.0044 & -0.0033 & -0.0022 & -0.0037 \\
I & PLH & 0.0027 & 0.0014 & 0.0046 & - & 0.0025 & 0.0015 & 0.0027 \\
I & CRY & -0.0104 & -0.0110 & -0.0173 & -0.0126 & - & -0.0034 & -0.0336 \\
I & DMC & 0.0058 & 0.0278 & 0.0572 & 0.0383 & 0.0175 & - & 0.0198 \\
I & FRY & 0.3391 & 0.3403 & 0.5116 & 0.3666 & 0.9014 & 0.1058 & - \\
\hline${ }^{*}{ }^{2}$ & 0.9792 & & & & & & & \\
${ }^{*}$ RVE & 0.1438 & & & & & & & \\
\hline
\end{tabular}

${ }^{*} \mathrm{R}^{2}$ - coefficient of determination; ${ }^{\sharp} \mathrm{RVE}$ - residual variance effect. VIG: plant vigor; LFR: leaf retention; AGY: above-ground yield; PLH: plant height; CRY: commercial fresh root yield; DMC: dry matter content; FRY: total fresh root yield.

FRY contributed indirectly to the estimates of those correlation coefficients. Therefore, the interpretation based solely on the magnitude of the correlation coefficients might result in misconceptions in the process of indirect selection of cassava genotypes for higher STY.

In the path analysis for VIG, LFR, AGY, PLH and CRY, the magnitude of the direct effect on STY was smaller than the residual variance effect (Table II). This indicates that an association between the traits may not be relevant, so that indirect selection considering these traits to increase STY will not result in genetic gains. On the other hand, the use of shoot traits in an indirect selection process in cassava can increase fresh root yield as well as starch yield (Gomes et al. 2007, Mulualem and Ayenew 2012). In addition, Lenis et al. (2006) reported that plants with greater shoot development and greater leaf retention tend to produce more photoassimilates, so there is an increase in the accumulation of dry matter content and consequently the production of starch in the roots. Thus, plants with higher leaf retention during development had higher harvest index and an average yield of $25 \%$ more roots compared to plants with lower leaf retention.

Commercial fresh root yield is an important trait to consider in the selection process when the objective is to produce cassava clones for the in natura market. On the other hand, for industrial purposes, CRY has little importance in comparison with the total fresh root yield. Although a high correlation was observed between CRY and STY (Figure 1), its direct effect on STY was negative and of low magnitude (Table II). Consequently, it can be affirmed that CRY is not a trait that should be used for indirect selection to increase starch yield.

The dry matter content of the roots is an important trait for the selection of superior cassava clones (Ceballos et al. 2016a, Freitas et al. 2016), and it has been associated to the root storage capacity. There was a direct and significant positive effect between DMC and STY (0.18), whose estimate was lower than the 
genetic correlation between these traits (0.29) (Figure 1, Table II). Despite having larger magnitude than the estimate of the residual variance effect, the indirect selection through DMC does not seem suitable to increase STY, considering the low magnitude of its direct effect.

FRY had the greatest direct effect on STY (0.97), corroborating the high genetic correlation between these two traits (Table II). In addition, the indirect effects of other traits on FRY were low. Therefore, the indirect selection for STY can be efficient considering only FRY. From a practical point of view, indirect selection can bring benefits due to the elimination of a trait that is difficult, expensive and time-consuming to measure when evaluating and selecting superior genotypes, sparing physical and financial resources so that more genotypes can be phenotyped in agronomic experiments.

\section{CORRELATED RESPONSE}

An important aspect in applying indirect selection in breeding programs is related to gain from direct selection and correlated response. In the literature on indirect selection of cassava, no practical information has been presented on its use (Gomes et al. 2007, Mulualem and Ayenew 2012, Ojulong et al. 2010). Therefore, we estimated the correlated response and the gain with direct selection by using the estimator proposed by Falconer and Mackay (1996). For this purpose, we used a selection intensity equal to 30\% for both correlated response and direct selection, along with values of $\mathrm{h}_{\mathrm{m}}^{2}$ for FRY $(0.42)$ and for STY $(0.43)$, as presented in the Table I, and used the genetic correlation coefficient between the two traits (0.97), as shown in the Figure 1. After applying these values, the ratio between the correlated response and the gain with the direct selection was 0.95 , indicating that direct selection based on STY is more efficient than indirect selection through FRY to select genotypes with higher STY.

Indirect selection can only be more efficient than direct selection if the $\mathrm{h}_{\mathrm{m}}^{2}$ of STY is much lower than the $\mathrm{h}_{\mathrm{m}}^{2}$ of FRY, which is not available for evaluating cassava accessions. However, the results of single-row trials conducted by Embrapa Mandioca and Fruticultura, the estimate of heritability for FRY was superior to that of STY (Freitas et al. 2018), which allows us to infer that in this case indirect selection could be efficient. For the other phases of cassava breeding, such as preliminary yield trials, advanced yield trials and uniform yield trials, which have similar estimates of the heritability coefficient for FRY and STY, indirect selection based on FRY would not be an effective strategy for selecting clones with higher STY.

Considering that indirect selection of STY by FRY may be efficient in cassava, in theory the adoption of a moderate selection intensity would increase the number of selected genotypes, without discarding the best genotypes selected directly via STY. However, in the cassava breeding program, this efficiency has little practical appeal, since STY is indirectly obtained by multiplying FRY and DMC that are evaluated late crop (during harvested at the $12 \mathrm{MAP}$ ). The correlation between FRY and STY is high and positive, whereas STY and DMC have low estimates of genetic correlation and low direct effect of DMC on STY. In addition, there was low indirect effect of FRY on DMC. However, the DMC should be evaluated, especially at advanced stages of the cassava breeding program because the Brazilian starch industries use this trait as a criterion for farmers' remuneration. Cassava root with high DMC implies can optimize can reduce the transportation costs per ton of starch and therefore increase the net profit. In addition, the indirect selection through FRY can also be compromised by the low correlation between FRY and DMC, since the selection of genotypes with high FRY does not imply the selection of genotypes with high DMC.

The cassava breeding program of CIAT (International Center for Tropical Agriculture) has used indirect selection based on the harvest index to select genotypes with higher total fresh root yield (Barandica et al. 
2016). This approach has been used by the breeders since 2000 due to the results published by Kawano et al. (1998), which showed that higher genetic gains could be obtained through indirect selection. However, Barandica et al. (2016) analyzed a dataset of the CIAT cassava breeding program containing information from the experiments of all clonal evaluation phases from 2000 to 2013. They observed a low magnitude of the estimated correlations between the harvest index and the total fresh root yield, mainly between single-row trials and uniform yield trials. Based on these results, the authors concluded that indirect selection based on the harvest index to increase total fresh root yield results in lower gains than selection based directly on total fresh root yield. Therefore, the CIAT cassava breeders stopped using indirect selection and started measuring the harvest index in single-row trials.

\section{GENERAL CONSIDERATIONS}

In cassava breeding programs, there is a need to evaluate a large number of clones in early stages of selection, since the increase in the number of individuals per family raises the chances of identifying superior clones (Ceballos et al. 2016b). This also increases the evaluation work and costs in each selection cycle. Indirect selection can thus be a viable approach, since discarding variables that present low heritability and are hard and costly to measure favors the selection of high performance clones. The findings in the present study show that indirect selection to increase STY is not efficient if FRY is used as selection criterion. However, the inclusion of other agronomic and morphological traits in path analysis as well as the use of more accurate phenotyping methods can be incorporated into the routine of breeding programs to reduce the number of traits evaluated in large populations as well as increase the precision of the indirect selection process. Among new technologies, ground-penetrating radar has been used as a nondestructive technique to predict the presence and number of roots in several plant species (Delgado et al. 2017), and it has enormous potential of use to measure FRY and indirectly STY. However, the results presented here can guide plant breeders in selecting cassava clones, as well as serve as a reference for future research.

\section{ACKNOWLEDGMENTS}

The authors thank the Fundação de Amparo à Pesquisa do Estado da Bahia (FAPESB), Coordenação de Aperfeiçoamento de Pessoal de Nível Superior (CAPES) and Conselho Nacional de Desenvolvimento Científico e Tecnológico (CNPq) for the financial assistance and scholarship support.

\section{AUTHOR CONTRIBUTIONS}

RPD conceived of the presented idea. EJO encouraged RPD to investigate the path analysis and genetic parameters and supervised the findings of this work. Both authors discussed the results and contributed to the final manuscript.

\section{REFERENCES}

BARANDICA OJ, PÉREZ JC, LENIS JI, CALLE F, MORANTE N, PINO L, HERSHEY CH AND CEBALLOS H. 2016. Cassava breeding II: phenotypic correlations through the different stages of selection. Front Plant Sci 7: 1-11.

CEBALlOS H, LÓPEZ-LAVALLE LAB, CALLE F, MORANTE N, OVALLE TM AND HERSHEY C. 2016a. Genetic distance and specific combining ability in cassava. Euphytica 210: 79-92. 
CEBALLOS H, MORANTE N, SÁNCHEZ T, ORTIZ D, ARAGÓN I, CHÁVEZ AL, PIZARRO M, CALLE F AND DUFOUR D. 2013. Rapid cycling recurrent selection for increased carotenoids content in cassava roots. Crop Sci 53: 1-10.

CEBALLOS H, PÉREZ JC, BARANDICA OJ, LENIS JI, MORANTE N, CALLE F, PINO L ANDHERSHEY CH. 2016b. Cassava Breeding I: the value of breeding value. Front Plant Sci 7: 1-12.

CRUZ CD. 2013. GENES - a software package for analysis in experimental statistics and quantitative genetics. Acta Sci Agron 35: 271.

CRUZ CD, REGAZZI AJ AND CARNEIRO PCS. 2012. Modelos biométricos aplicados ao melhoramento genético. $4^{\mathrm{a}}$ ed., Viçosa, MG: UFV, p. 276.

DELGADO A, HAYS DB, BRUTON RK, CEBALLOS H, NOVO A, BOI E AND SELVARAJ MG. 2017. Ground penetrating radar: a case study for estimating root bulking rate in cassava (Manihot esculenta Crantz). Plant Methods 13: 1-11.

ESUMA W, KAWUKI RS, HERSELMAN L AND LABUSCHAGNE MT. 2016. Diallel analysis of provitamin A carotenoid, dry matter content in cassava (Manihot esculenta Crantz). Breed Sci 66: 627-635.

FALCONER DS AND MACKAY TFC. 1996. Introduction to quantitative genetics. Longmans Green, Malaysia, 463 p.

FREITAS JPX, DINIZ RP, SANTOS VS AND OLIVEIRA EJ. 2018. Genetic parameters and selection gains in early clonal evaluation trials: implications for cassava breeding. Euphytica 214: 127.

FREITAS JPX, SANTOS VS AND OLIVEIRA EJ. 2016. Inbreeding depression in cassava for productive traits. Euphytica 209: $137-145$.

GOMES CN, CARVALHO SP, JESUS AMS AND CUSTÓDIO TN. 2007. Caracterização morfoagronômica e coeficientes de trilha de caracteres componentes da produção em mandioca. Pesqui Agropecu Bras 42: 1121-1130.

KAWANO K, FUKUDA WMG AND CENPUKDEE U. 1987. Genetic and environmental effects on dry matter content of cassava root. Crop Sci 27: 69-74.

KAWANO K, NARINTARAPORN P, SARAKARN S, LIMSILA A AND LIMSILA J. 1998. Yield improvement in a multistage breeding program for cassava. Crop Sci 38: 325-332.

LENIS JI, CALLE F, JARAMILLO G, PEREZ JC, CEBALLOS H AND COCK JH. 2006. Leaf retention and cassava productivity. Field Crops Res 95: 126-134.

MONTGOMERY DC, PECK EA AND VINING GG. 2012. Introduction to linear regression analysis. J Wiley \& Sons, Hoboken, $672 \mathrm{p}$.

MULUALEM T AND AYENEW B. 2012. Correlation, path coefficient analysis of cassava (Manihot esculenta Crantz) at Jimma, Southwestern, Ethiopia. J Nat Sci Res 2: 1-7.

NUWAMANYA E, BAGUMA Y, KAWUKI RS AND RUBAIHAYO PR. 2009. Quantification of starch physicochemical characteristics in a cassava segregating population. Afr Crop Sci J 16: 191-202.

OJULONG HF, LABUSCHAGNE MT, HERSELMAN L AND FREGENE M. 2010. Yield traits as selection indices in seedling populations of cassava. Crop Breed Appl Biotechnol 10: 191-196.

OLIVEIRA EJ, SANTANA FA, OLIVEIRA LA AND SANTOS VS. 2014. Genetic parameters and prediction of genotypic values for root quality traits in cassava using REML/BLUP. Genet Mol Res 13: 6683-6700.

R DEVELOPMENT CORE TEAM. 2016. R: a language, environment for statistical computing. R Foundation for Statistical Computing, Vienna. Available at: http://www.R-project.org. Accessed in May, 2016.

RESENDE MDV. 2016. Software Selegen-REML/BLUP: a useful tool for plant breeding. Crop Breed Appl Biotechnol 16: 330-339. RESENDE MDV AND DUARTE JB. 2007. Precisão e controle de qualidade em experimentos de avaliação de cultivares. Pesqui Agropecu Trop 37: 182-194.

TOKATLIDIS IS. 2017. Crop adaptation to density to optimize grain yield: breeding implications. Euphytica 213: 1-25. 